\title{
IMPEDIMENTO? POSSIBILIDADES DE RELAÇÃO ENTRE A MULHER E O FUTEBOL
}

\author{
Impediment? Possibilities of relationship between women and football
}

¿Impedimento? Las posibilidades de relación entre las mujeres y el fútbol

LARISSA MEDEIROS DE SOUZA

ANA ANDRÉA BARBOSA MAUX

MELINA SÉFORA SOUZA REBOUÇAS

\begin{abstract}
Resumo: O futebol é uma paixão nacional. Mais do que um mero jogo, essa prática esportiva de origem britânica foi "abrasileirada” ao ponto de ser considerada uma expressão de nossa cultura e característica de nossa identidade nacional. Na realidade brasileira, o mundo da bola, apesar de representar toda uma nação, ainda demonstra abarcar um público específico - os homens -, deixando à margem a participação das mulheres, que buscam um lugar de visibilidade e respeito. Elas, assim como eles, participam do futebol de diversas maneiras, entretanto ainda possuem entraves nessa relação. O presente artigo, de caráter teórico, apresenta uma construção histórica acerca do futebol e da participação feminina no mesmo. Discute, ainda, os papéis e espaços das mulheres que torcem, jogam, arbitram, comandam e dirigem clubes de futebol. Por fim, é possível refletir, a partir da perspectiva fenomenológico-existencial heideggeriana, a participação das mulheres no contexto do futebol como Dasein, que possuem abertura de mundo e sentido de poder-ser. Palavras-chave: Futebol; Gênero; Mulher; Fenomenologia.
\end{abstract}

Abstract: Football is a national passion. More than just a game, this sport of British origin, was "abrasileirada" to the point of being considered an expression of our culture and characteristic of our national identity. In the Brazilian reality, the world of the ball, although it represents an entire nation, it still shows a specific audience - men - leaving aside the participation of women, who seek a place of visibility and respect. Women, as well as men, participate in football in a variety of ways, However, there are still obstacles in this relationship. This article, of a theoretical nature, presents a historical construction about football and concerning female participation in the game. It also discusses the roles and spaces of women who cheer, play, referee, command and direct football clubs. Finally, it is possible to reflect, from the perspective of heideggerian existencial phenomenological, the participation of women in the context of football like $\mathrm{Da}$ sein, who has openness to the world and a sense of being-power.

Keywords: Football; Gender; Woman; Phenomenology.

Resumen: El fútbol es una pasión nacional. Más que un juego, esta práctica deportiva de origen británico fue "abrasileirada" hasta el punto de ser considerada una expresión de nuestra cultura y la característica de nuestra identidad nacional. En Brasil, el mundo de la pelota de fútbol, apesar de representar a una nación entera, también muestra abarcar un público específico - hombres - dejando de lado la participación de las mujeres, que buscan un lugar de visibilidad y respecto. Las mujeres como a los hombres, participan en el fútbol de muchas maneras, sin embargo, todavía tienen obstáculos en la relación. En este artículo, de carácter teórico, se presenta una breve historia sobre el fútbol y la participación de las mujeres. Se analiza también las funciones y espacios de las mujeres, que son hinchas, jugadoras, árbitros, entrenadoras y dirigentes de los clubes de fútbol. En último, se puede reflexionar, desde la perspectiva existencial-fenomenológica de Heidegger la participación de las mujeres en el contexto de fútbol como Dasein, que tiene el mundo de la apertura y la sensación de poder-ser. Palabras-clave: Fútbol; Género; Mujer; Fenomenología.

\section{Introdução: Convocação e aquecimento}

Em fevereiro de 2016, na ocasião do lançamento dos uniformes do Clube Atlético Mineiro, houve, nas redes sociais e noticiários, polêmicas envolvendo a apresentação dos mantos alvinegros. As modelos, todas mulheres, que desfilaram com as camisas do Galo, vestiam calcinhas, o que gerou certo desconforto em alguns presentes, e terminou por evidenciar a falta de tato do clube em lidar com suas torcedoras ao realizar um evento voltado essencialmente ao público masculino - sem mencionar a objetificação do corpo feminino. Além da configuração da apresentação, os uniformes expostos continham, em sua etiqueta, a seguinte instrução give to your wife, ou seja, dê para sua mulher (lavar).

A exposição desse caso nos levou a refletir acerca das influências patriarcais que ainda estão presentes em nossa sociedade e refletidas no futebol, colocando a mulher em um não-lugar ou um não-lugar de protagonismo, na relação com essa prática esportiva. Apesar do Brasil possuir fama mundial de ser O País do Futebol, é interessante notar que a palavra futebol é imediatamente associada à prática masculina. Para que saibam se tratar do 
futebol praticado por mulheres, é preciso acrescentar o termo feminino como adjetivo. É possível perceber que o mesmo não ocorre em outros esportes, como o vôlei ou o basquete. A alcunha que o Brasil carrega é generalizada, ao menos na teoria, mas percebemos que, na prática, ela termina abrangendo somente o universo dos homens. Por quê? Ainda temos um obstáculo de gênero a superar. Pretende-se, neste artigo, explanar e discutir, à luz da fenomenologia, sobre o papel que as mulheres ocupam e sobre a relação que elas estabelecem na vivência de ser torcedoras, atletas, árbitras, técnicas e dirigentes de clubes de futebol.

O Dasein, também compreendido como ser-aí e ser-no-mundo, é o termo utilizado por Heidegger (Heidegger, 1927/2015) para designar o modo de ser humano, como sendo abertura e estando sempre em relação com o próprio ser e com o mundo - não sendo possível dissociar ambos (Roehe \& Dutra, 2014). De acordo com Sá (2005), Heidegger aponta para uma ausência de essência determinada $a$ priori no Dasein, diferentemente do que acontece com os entes que não possuem o modo de ser do homem - sendo o homem o que é, através do existir. Dessa forma, o filósofo considera a diferença ontológica - aquela que propõe a distinção entre ser e ente como a mais significativa, sobrepondo-se a outras categorias de diferenças (Rodrigues, 2010), como o gênero. A partir dessa ideia, podemos refletir que, não havendo determinação prévia do ser humano e sendo ele constituído através do seu existir - em relação consigo e com o mundo - a categorização do humano em grupos de gêneros, que ditam os seus modos-de-ser no mundo, nada mais é do que uma característica cultural, que apresenta como definitivo alguns modos-de-ser homem e de ser mulher, sendo outras possibilidades existenciais vistas como marginais (Maux, 2014). Assim sendo, o que trazemos deste artigo a título de reflexão é justamente considerarmos as possibilidades de se existir como mulher habitando o chamado universo do futebol, que culturalmente é visto como um espaço masculino por excelência.

De origem inglesa, o que hoje chamados de futebol teve início no fim do século XII, com o chutar de uma bola simbolizando, na época, a cabeça de comandantes dinamarqueses expulsos da Inglaterra, e progressivamente foi ganhando popularidade (Elmôr, 2002). Em 26 de outubro de 1863 foi fundada a Football Association, havendo a regulamentação das regras do futebol e o seu reconhecimento como esporte (Oliveira, 2012). Uma vez instituído, o futebol passou a ser valorizado por pedagogos, que viam nessa prática a oportunidade de ocupar os alunos, bem como proporcionar o cultivo de virtudes e da virilidade (Elmôr, 2002). Podemos observar que o emprego da palavra virilidade nos indica, já nessa época, que a prática do futebol era voltada exclusivamente para os meninos.

Após sua regulamentação, o futebol passou a ser praticado pela elite aristocrática, porém, posteriormente, foi amplamente difundido pelas demais camadas da sociedade britânica, atraindo um público predominantemente masculino, e passou a ser mais organizado, com a profissionalização de atletas (Elmôr, 2002).

Segundo Oliveira (2012), foi em 1894 que o futebol chegou ao Brasil, através do paulista Charles Miller - considerado o pai desse esporte em nosso país. O jovem chegara de temporada de estudos na Inglaterra, trazendo consigo bolas, uniformes, um apito e o manual de regras do jogo. Assim como ocorreu na Europa, o futebol era considerado um esporte de elite, atraindo os jovens abastados que se filiavam a clubes esportivos e escolas que propiciavam espaços de lazer e socialização.

Em seu retorno, Charles Miller encontrou um país republicano, não mais escravocrata, e que utilizava mão de obra estrangeira e assalariada. Este novo contexto político e socioeconômico propiciou um aumento populacional nos centros urbanos, especialmente de negros, mulatos e brancos pobres o que, por sua vez, determinou uma reforma urbana com a ampliação de espaços ao ar livre para a socialização e prática esportiva (Oliveira, 2012).

Apesar da influência de Miller na implementação do futebol em São Paulo, e de Oscar Cox no Rio de Janeiro, outros movimentos ocorreram em todo o Brasil em meados do fim do século XIX e início do século XX. Um dos primeiros times de futebol criados no país foi o Sport Club Rio Grande, do Rio Grande do Sul, tendo como um de seus fundadores o alemão Johannes Christian Moritz Minnemann, em 1900 (Correia \& Rigo 2013). Na Bahia, o futebol passou a ganhar espaço nos clubes de críquete, tendo o Club de Cricket Victória, fundado em 1899, mudando seu nome para Sport Club Victória em 1901 e adotado o futebol como prática no ano seguinte (Rocha Junior \& Santo, 2011). Dessa forma, a disseminação do futebol não demorou a ocorrer no Brasil.

\section{Preleção}

Os papéis de gênero foram, ao longo da história, sendo estabelecidos e modificados nas sociedades, em todo o mundo. Comumente patriarcal, a maioria das sociedades, especialmente as ocidentais, instituíam papéis diferentes para homens e mulheres: as atribuições domésticas e maternas eram destinadas às mulheres, cabendo aos homens, viris e másculos, a atividade de prover a família, através do trabalho. Ao trazermos uma reflexão à luz da hermenêutica heideggeriana para essa discussão, é possível entendermos que essa essência apriorística, que diz ao homem e à mulher quem são e como devem se portar, é um retrato do horizonte histórico que se atravessa em nosso cotidiano (Rebouças \& Dutra, 2017). Restritas a permanecerem no espaço do lar, sem querer ou poder próprios, à sombra dos homens e devendo obediência aos mesmos, as mulheres passaram a se organizar, incialmente, na luta por direitos igualitários, criando um amplo movimento que, até os dias de hoje, busca legitimar seu espaço na sociedade - um espaço sem distinção de gênero, onde as pessoas possam ter a liberdade de poder-ser. Nesse sentido, a parti- 
cipação das mulheres nas práticas esportivas, como veremos, também precisou ser conquistada.

De acordo com Oliveira (2006), as primeiras competições esportivas que se tem conhecimento são os Jogos Pan-Helênicos, ocorridos na Grécia Antiga. Nessa época, a participação das mulheres nos jogos era proibida, nem mesmo como espectadoras. Na primeira edição dos Jogos Olímpicos Modernos, realizado na cidade de Atenas em 1896, participaram 245 atletas masculinos de 14 países e havendo a exclusão das atletas femininas por opção do seu idealizador, o francês Barão Pierre de Cobertin (Miragaya, 2008). O desejo de Cobertin, entretanto, não durou muito tempo, pois na edição seguinte das Olimpíadas, em 1900, na França, as mulheres se fizeram presentes e representavam inexpressivos, porém significativos, $2 \%$ do total de atletas, sendo Charlotte Cooper, tenista britânica, a primeira mulher a ser medalhista olímpica, conquistando o ouro (Senkevics, 2012).

Ao fim do século XIX e no decorrer do século $\mathrm{XX}$, “as mulheres começaram a conquistar novas posições em seus países, tornando-se mais ativas, e (...) pouco a pouco (...) começaram a invadir uma área que nunca lhes havia pertencido e que lhes era bastante atraente" (Miragaya, 2008, p. 230). Os avanços nos direitos das mulheres contribuíram, também, para o crescente número de participantes femininas nas Olimpíadas, bem como para impulsão de sua visibilidade. Â medida em que foram sendo realizados os Jogos Olímpicos, o número de atletas femininas, assim como o leque de modalidades destinado a elas, foi sendo ampliado mediante muito esforço (Oliveira, 2006). A edição de 2012, sediada em Londres, ficou conhecida como A Olimpíada das Mulheres pois, primeira vez, todos os 204 países e territórios participantes possuíam mulheres integrando suas delegações. Além disso, o número de atletas femininas alcançou $44 \%$ do total de atletas inscritos - ou 4.620, em um universo de 10.500 (Duque \& Hedler, 2012).

Assim como a maioria dos esportes, o futebol, desde que aportou no Brasil, foi associado, e é alimentado até os dias de hoje, como prática esportiva masculina. Em nosso país, até meados do século XIX, as mulheres pouco eram vistas na esfera pública. A partir da segunda metade do referido século, impulsionadas pela modernidade vinda da Europa e pelo processo de urbanização dos centros brasileiros, as mulheres passaram a ocupar mais espaços públicos e ter participação mais ativa na vida social. Foi nessa época que passaram a ser expectadoras dos esportes praticados pela elite brasileira, tais como o remo, o turfe e, posteriormente, o futebol (Melo, 2007).

A participação das mulheres nos clubes estava restrita às esposas e filhas solteiras dos associados que, como dependentes, possuíam livre acesso aos jogos de futebol, espaço propício para a socialização e flerte com bons partidos (Santos, 2010). O autor ainda aponta, acerca do comportamento das moças nesses eventos, que todas compareciam muito elegantes e, costumeiramente, assistiam às partidas gesticulando, gritando o nome de seus atletas preferidos e torcendo o que traziam em mãos. Tal característica chamou a atenção da sociedade e da impressa, trazendo à tona um importante personagem do futebol: a torcedora.

Com o processo de popularização do futebol, aos poucos as classes menos abastadas foram adquirindo espaço nas arquibancadas, sendo responsabilizadas pela onda de violência que veio a se fazer presente nos estádios. Foi nesse momento, por volta de 1920, que as mulheres e as famílias passaram a ser menos presentes nesses espaços (Santos, 2010). A partir disso, e do advento das torcidas organizadas, com suas expressões de violência, pós 1970, os estádios passaram a ser consolidados como arenas da masculinidade, havendo presença de mulheres quando acompanhadas por um parente homem e em locais específicos nos estádios (Stahlberg, 2013).

No tocante à inserção da mulher como praticante do futebol, Moura (2003) relembra que havia um discurso higienista e eugenista na época, afirmando os riscos e prejuízos que a prática esportiva trazia para o corpo da mulher. Dessa forma, os esportes permitidos para as mulheres - as da alta sociedade, que tinham acesso aos clubes - eram a natação e o tênis. Apesar dessa visão, o futebol estava sendo disseminado pelo país, inclusive entre as moças. $\mathrm{O}$ primeiro registro de futebol praticado por mulheres, o que não significa que não existiu alguma prática anterior a esse marco, é datado em 28 de junho de 1921, entre as Senhoritas Tremembenses x Senhoritas Cantareirenses, em São Paulo (Moura, 2003).

A persistência nas supostas preocupações com o bem-estar físico das mulheres, que na realidade, buscava abafar a subversão de papéis que estava ocorrendo: as mulheres deixando suas funções domésticas naturais para adentrar em espaços tipicamente masculinos (Franzini, 2005), causou repercussões legais. Em abril de 1941 foi instituído o decreto-lei 3.199, que criou o Conselho Nacional de Desportos (CND) e indicou, em seu artigo 54, a não permissão de práticas desportivas incompatíveis com a natureza feminina, cabendo ao CND às instruções necessárias para tal prática (Decreto Lei $\mathrm{n}^{\mathrm{o}}$ 3.199/1941). Em 1965, o CDN regulamentou algumas instruções, entre elas a que proibia a prática de algumas modalidades, inclusive o futebol, pelas mulheres (Castellani Filho, 1988). Buscando compreender os sentidos dessa proibição, é importante considerar que o horizonte histórico em que as mulheres estão inseridas, as limitam ao papel da procriação e da maternidade, aprisionando-as em um dever ser e restringindo-se o poder-ser (Rebouças \& Dutra, 2017).

As proibições terminaram por contribuir, segundo Moura (2003), com a ausência do futebol nas atividades físicas escolares para as meninas. $\mathrm{O}$ autor explica que não necessariamente esta prática estava presente no currículo das turmas de garotas, mas devido ao momento do futebol no país, uma boa oportunidade de aproximação entre ambos foi tolhida. O CDN revogou a proibição da prática do futebol por mulheres somente em 1979, havendo, no início dos anos 80, uma reconfiguração da situação daquelas que se interessavam pelo futebol (Deliberação no 10/1979). 


\section{Organização tática}

A entrada das mulheres no universo do futebol se deu, como visto, através dos papéis de torcedora e jogadora, sendo eles os mais clássicos e populares. Ao longo do tempo, foram surgindo outros espaços de inserção, como na arbitragem, hoje considerada em alta e reconhecidamente em ascensão (Confederação Brasileira de Futebol, 2014); no comando técnico de times, papel que ganhou mais visibilidade no período em que Emily Lima assumiu a seleção brasileira feminina principal; e na gestão do futebol, espaço ainda novo para a mulheres, mas que apresenta potencial de crescimento. Apresentamos, em cinco categorias que consideramos principais por sua relevância e notoriedade, a presença da mulher no futebol, trazendo seu percurso histórico, dificuldades e conquistas.

\section{As torcedoras}

Partindo das arquibancadas já foi apontado o pioneirismo das mulheres como torcedoras de futebol, bem como um breve percurso de sua inserção como espectadoras nos estádios. Hoje em dia, aponta Vieira (2010), as mulheres estão mais presentes nos estádios de futebol por todo o país, o que leva a crer que elas possuem mais liberdade de expressão nesse espaço e que vem diminuindo os questionamentos acerca da sua presença no mesmo. Atualmente, ver uma mulher no estádio ou vestindo a camisa do seu time não é considerado algo absurdo ou espantoso. Entretanto, a qualidade e as intenções desse torcer ainda são questionadas por muitos homens, fazendo com que as mulheres busquem se apropriar desse espaço para não dar brecha à desconfiança masculina (Stahlberg, 2013). É como se os homens, e até outras mulheres, permitissem e aceitassem a participação das torcedoras nos estádios, mas sua capacidade de compreensão em relação ao jogo é sempre duvidosa. Nesse sentido, as mulheres procuram legitimar o seu interesse como verdadeiro, passando pelos constantes questionamentos acerca da história do seu clube de coração, escalação, esquemas táticos e, claro, as regras do jogo (Stahlberg, 2013) - afinal, quem nunca perguntou a uma mulher se ela sabe o que é impedimento?

As constantes provas que a torcedoras necessitam dar acerca do seu amor e interesse pelo futebol também passa pela tentativa de romper com os estereótipos aplicados a elas. Em pesquisa realizada com torcedoras, Stahlberg (2013) apresenta três imagens que são frequentemente associadas às mulheres que torcem. Elas, por sua vez, buscam legitimar seu status de verdadeira torcedora afastando de si as imagens de modinha, maria-chuteira e mulher-macho. A torcedora modinha é definida como aquela que alega ter um time, especialmente quando o mesmo se encontra em boa fase, entretanto pouco acompanha ou possui conhecimento sobe ele. A maria-chuteira, apesar de também dizer que possui um time e ir ao estádio, na realidade apresenta maior interesse nos jogadores do que no jogo em si. Já a denominação maria-macho faz referência às mulheres que gostam de futebol e que são vistas como masculinizadas ou homossexuais por causa disso (Stahlberg, 2013). Percebemos aqui, que além de ter que lidar e romper com os papéis atribuídos ao ser mulher quando consideramos seu horizonte histórico, as mulheres, por serem seres-com e seres-no-mundo, se veem em uma rede de significados e determinações quando se inserem no universo do futebol.

Vieira (2010) também realizou uma pesquisa com torcedoras de futebol. Nos discursos analisados pelo autor foi possível apreender alguns sentimentos, inclusive a auto percepção das mulheres em relação a sua condição de torcedora. Algumas falas apontam no sentido do preconceito existente, por parte dos homens, às frequentadoras de estádios. Vistas como estrangeiras em um reduto essencialmente masculino, as mulheres são comumente questionadas sobre o seu saber, para ser constatado se é merecedora ou não de se fazer presente no templo do futebol. As entrevistadas corroboraram com a percepção de que os estádios são vistos como espaços masculinos - até pela maioria numérica deles, entretanto ponderaram que esses locais podem, e devem, ser frequentados também pelas mulheres, configurando-se como um espaço democrático. Acerca da percepção de suas vivências como torcedoras, as mulheres apontam para o sentimento de privilégio pela conquista de espaços, inclusive no futebol, modificando um anterior quadro de exclusão. No que se refere ao ato de torcer propriamente dito, as entrevistadas sentem que vivenciam o espetáculo e a emoção da mesma forma dos homens, cultivando, evidentemente, a paixão pelo seu clube do coração.

A despeito de estar construindo uma relação cada vez mais efetiva com o futebol, as torcedoras parecem não ter chamado a atenção dos dirigentes dos clubes brasileiros. Sobre isso, Moreira e Pedrosa (2016) afirmam, levando-se em consideração as poucas e antigas pesquisas existentes sobre o perfil da mulher que torce, que os clubes realmente não conhecem as torcedoras que tem - tampouco se dedicam a ações voltadas a elas, exceto no Dia Internacional da Mulher. É comum, ao se entrar em qualquer loja de clube ou mesmo de artigos esportivos, perceber a grande variedade de produtos pensados para os homens, desde o vestuário até os acessórios, e a escassez de materiais voltados para as mulheres e crianças. As torcedoras, especificamente, parecem estar abrindo caminhos para a consolidação de sua presença no mundo do futebol, como temos visto, entretanto, ainda não parecem ser enxergadas por aqueles que comandam esse mundo.

\section{As jogadoras}

Sobre a prática do futebol de mulheres no Brasil, podemos dizer que ela passou a ser aceita, de fato, pós 1979. Entretanto, foi somente em 1988 que a Federação Internacional de Futebol (FIFA) organizou, na China, seu primeiro torneio internacio- 
nal voltado para esse público. Em 1991 foi sediada, também na China, a primeira Copa do Mundo de Futebol Feminino (Franco Júnior, 2007) evidenciando o quão recente é a imersão organizada e permitida das mulheres enquanto atletas de futebol.

Klessler (2015) aponta para a dificuldade da uma construção linear da história no futebol de mulheres no Brasil, constatando a pouca sistematização de registros acerca dessa prática. Apesar disso, é perceptível que ela está entrelaçada com o Esporte Clube Radar, do Rio de Janeiro. Fundado em 1932 como um time de futebol de praia, foi em 1981 que o Radar, por incentivo de seu presidente, Eurico Lira, criou o seu time feminino - incialmente, também de praia, ganhando os campos posteriormente (Echevrerria, 1984). Segundo Duarte, Garcia e Luz (1996) o Radar construiu, ao longo da década de 80, a fama de time imbatível, contabilizando apenas 4 derrotas em 300 partidas e a conquista de dois pentacampeonatos carioca e brasileiro, sendo extinto em 1988. A equipe do Radar constituiu importante base para o futebol de mulheres, pois suas atletas representavam o Brasil em competições internacionais no fim da década de 80 (Souza, 2013). A década de 90 seguiu a tendência da anterior, criando grande mobilização em torno do futebol feminino. Em 1996, o futebol feminino debutou nos Jogos Olímpicos, na edição de Atlanta - 88 anos após a inclusão do futebol de homens na mesma competição (Klessler, 2015).

A trajetória das mulheres que se interessam por futebol ou desejam ser jogadoras, é permeada pela proibição desde a idade escolar. Moura (2003) chama atenção para a dificuldades das meninas, nas aulas de educação física, em adentrar no universo do futebol, mesmo este sendo considerado uma expressão da nossa cultura. Em pesquisa realizada por Wenetz (2005) sobre gênero e sexualidade nas brincadeiras do recreio, a autora constatou a existência da polarização das brincadeiras por gênero, através da fala das crianças, bem como o desejo de algumas delas de pertencer, também, ao universo do gênero oposto, como mostra a fala a seguir:

(...) perguntei a duas meninas: "há brincadeiras de meninos"? E Letícia me respondeu: "a brincadeira de meninos que eu mais gosto é o futebol". Perguntei: "você gosta de futebol?" Letícia: "é, mas de que adianta brincar, se daí nós ficamos num grupo e os meninos em outro, não tem ninguém pra brincar" (Wenetz, 2005, p; 161)

Diante da dificuldade em participar de um esporte dito masculino em uma recreação infantil, imaginamos as barrerias que precisam ser ultrapassadas por aquelas que almejam praticar e se profissionalizar no futebol. Escolinhas de futebol voltadas para o público femininos são escassas ou inexistentes, sendo aquelas meninas mais ousadas e talentosas, aceitas, nem sempre sem custos, em escolinhas masculinas para a formação de times mistos. Em sua obra Ensaios e Conferências, Heidegger nos leva a refletir acerca do habitar. Inicialmente, o autor nos traz que o habitar é a meta do construir, como na construção de uma ponte, por exemplo, entretanto, ao considerarmos as relações essenciais, vemos que o esquema meio-fim não pode representa-las adequadamente, uma vez que "construímos e chegamos a construir à medida que habitamos, ou seja, à medida que somos como aqueles que habitam" (Heidegger, 2012, p. 129). Dessa forma, entendemos que a relação entre construir e habitar é íntima, o que nos leva a refletir, na situação em questão, que estabelecer uma prática futebolística voltada para as mulheres exige um habitar esse espaço para a construção do mesmo.

\section{As árbitras}

O primeiro registro de arbitragem feminina em todo o mundo ocorreu no Brasil. Asaléa Campos Michelli passou a atuar nos gramados após realizar um curso oferecido pelo Departamento Amador da Federação Mineira de Futebol, em 1967. Devido às imposições da Confederação Brasileira de Desportos (CBD) acerca da prática esportiva de mulheres, Asaléa não obteve seu diploma após concluir o curso. Em 1971 veio o convite da FIFA para apitar um torneio amador de futebol feminino no México, porém a árbitra teria que ter o aval da confederação nacional. Ela foi buscar a autorização direto com Médici, comandante do país na época, que escreveu de próprio punho uma carta ao então presidente da CBD, João Havelange, para que houvesse a liberação de seu diploma e, enfim, pudesse apitar, mesmo que no futebol amador (Mello, 2015). Assim como Asaléa, outro nome que merece destaque e cuja atuação abriu portas para a inserção das árbitras em jogos masculinos de grande importância, foi Silvia Regina de Oliveira. Em 2003, Silvia foi a primeira mulher a apitar um jogo da Série A do Campeonato Brasileiro, juntamente com outras duas assistentes, Aline Lambert e Ana Paula Oliveira, formando um trio de arbitragem totalmente feminino (Leite, 2017).

Entre o diploma de Asaléa e a primeira partida de destaque realizada por Silvia até os dias de hoje, muitos obstáculos foram enfrentados e conquistas realizadas. Stahlberg (2013) aponta que a arbitragem foi, dentro do futebol, o espaço mais bem-sucedido que as mulheres conquistaram, superando, inclusive as conquistas das mesmas profissionais de outros países. Apesar disso, ainda existe, a despeitos dos erros de arbitragem, uma tolerância mais baixa em relação às mulheres do que aos homens; assim como existe a cobrança de uma postura não masculinizada, porém não excessivamente feminina, que não faça a árbitra perder a autoridade dentro de campo (Stahlberg, 2013).

Essas colocações nos levam a refletir algumas questões acerca da mulher que atua dentro de campo. É esperado que ela seja discreta, porém deve provar competência a todo instante, pois seus erros também serão julgados por seu gênero, numa tentativa de comprovar certa ignorância e incapacidade para o cargo. Fisicamente, precisa buscar um meio 
termo: deve ser caracterizada como mulher, mas nem tanto, uma vez que os marmanjos não lhe dariam a devida credibilidade. Em suma, as mulheres árbitras e assistentes buscam atuar de acordo com o que é esperado de seu comportamento e, mesmo assim, parecem despertar somente duas visões na plateia: a beleza e o não saber/incompetência, pois quando não são gostosas ou uma delícia, elas devem ir lavar a louça ou ouvir um tinha que ser mulher...

Stahlberg (2013) afirma que, ao fazermos um comparativo entre árbitras principais e assistentes, as últimas parecem ter um espaço mais consolidado que as primeiras. Essa colocação parece ser corroborada pelos dados colhidos no site da Confederação Brasileira de Futebol (CBF), onde dos 227 árbitros cadastrados, apenas 16, ou 7,04\%, são mulheres. Em relação ao número de assistentes, as 53 mulheres representam 17,20\% do total de 308 inscritos. Esse quadro se configura a partir da dificuldade, por partes das Federações, jogadores e treinadores, em admitir que as mulheres podem imprimir autoridade e disciplina em uma partida de futebol masculino (Stahlberg, 2013). Assim fica a clara a diferença de poder entre o árbitro principal, dono do jogo e do apito, e seus auxiliares, coadjuvantes e subordinados. Sobre isso, Stahlberg (2013, p. 83) esclarece que sua "hipótese é de que as mulheres sejam melhor aceitas numa posição que seja mais discreta e de menor enfrentamento direto com os personagens de uma partida”.

\section{As técnicas}

Assim como em outros espaços, o comando técnico de um time de futebol, seja este praticado por homens ou mulheres, é predominantemente ocupado por pessoas do gênero masculino. Um exemplo disso pôde ser observado na Copa do Mundo feminina, disputada no Canadá em 2015. Das 24 seleções participantes, apenas um terço delas possuíam técnicas também mulheres (Rocha, 2015).

O percurso histórico das mulheres como técnicas de times de futebol ainda não parece estar minimamente consolidado, como já acontece em outros espaços. No Brasil, as experiências são esporádicas e até pouco expressivas, principalmente se lembrarmos que vivemos na pátria do futebol. O primeiro clube profissional brasileiro a ser liderado por uma mulher foi o Andirá Esporte Clube, do Acre. Em 2000, Cláudia Malheiro assumiu o comando técnico do clube e repetiu o feito em 2007, quando conseguiu o inédito vice-campeonato estadual com o morcego. Anteriormente, Cláudia havia trabalhado como auxiliar técnica no Vasco da Gama, também no estado acreano. No primeiro trimestre de 2013, pela primeira vez, uma mulher assumiu cargo de comando em uma Seleção Brasileira. Emily Lima passou comandar a Seleção Brasileira Feminina Sub-17 - posteriormente, também a categoria Sub15 (Confederação Brasileira de Futebol, 2013). A treinadora seguiu nas seleções até o início de 2015, quando aceitou a proposta para comandar o time feminino do São José, de São Paulo, no Campeonato
Brasileiro do mesmo ano, permanecendo no cargo em 2016 (FoxSports, 2015). A saída de Emily das seleções se deu por motivos financeiros: a CBF não pagava salário fixo à técnica, somente em época de competições (Mendonça, 2016).

Recentemente, em novembro de 2016, Emily Lima foi anunciada como a primeira treinadora de Seleção Brasileira Feminina Principal (Confederação Brasileira de Futebol, 2016), sendo a primeira a ocupar o mais alto escalão técnico feminino do país. O que, entretanto, parecia um prenúncio de boas mudanças para o futebol de mulheres veio por água abaixo 10 meses depois: Emily foi demitida sem, sequer, disputar uma competição oficial pela Seleção. Foram 13 jogos, 56,4\% de aproveitamento, e uma demissão após 3 derrotas em jogos amistosos contra a Austrália, uma das seleções que mais investe no futebol feminino, fora de casa (Dibradoras, 2017). Se Emily fosse João, será que teria tido mais tempo?

Apesar de, aparentemente, não ter agradado os mandatários da nossa Confederação de Futebol, a demissão de Emily repercutiu de tal maneira, que algumas jogadoras e ex-jogadoras da Seleção Brasileira se articularam e divulgaram uma carta de apelo dirigida à CBF buscando a colocação de mulheres em cargos de decisão da entidade (Mendonça, 2017). Além da carta, algumas jogadoras declararam publicamente que não servirão mais à Seleção Brasileira após a demissão de Emily e pelas más condições de trabalho (Observador, 2017), gerando grande repercussão nacional e internacional

A dificuldade de se encontrar material teórico, ou mesmo esportivo, sobre o tema, reflete a real falta de espaço para as mulheres que se propõem a comandar times de futebol, até mesmo nas categorias femininas. Mas qual a razão, efetivamente, para que a mulheres tenham dificuldades em adentrar esse espaço? Será que a vivência de 10 meses de Emily à frente da nossa Seleção Feminina foi o suficiente para que essa porta se feche novamente? Ou ainda pode se constituir como abertura?

\section{As dirigentes}

A construção de espaços para as mulheres no futebol vem sendo feito, através dos anos, em vários eixos. Um dos papéis mais complexos que a mulher pode exercer nesse universo é o de dirigente, a liderança máxima de um clube de futebol. A mais famosa gestão feminina no futebol foi a de Patrícia Amorim, eleita no fim de 2009 para comandar o Flamengo durante o triênio 2010-2012. Antes disso, outras mulheres se mostraram pioneiras na administração esportiva. Sobre a primeira delas a ocupar esse cargo do Brasil, Noronha (2012) aponta que essa experiência se deu em 1973 na cidade de Encantado, interior do Rio Grande do Sul, quando Jurema Bagatini Ramos assumiu o Esporte Clube Encantado, preste a falir, e o conduziu à primeira divisão do Campeonato Gaúcho. Já Marlene Callo Matheus foi a pioneira na direção de um grande clube do País. Entre 1991 e 1993 ela admi- 
nistrou o Sport Clube Corinthians Paulista. Esposa de Vicente Matheus, ex-presidente do alvinegro, a eleição de Marlene foi vista como alternativa para que Vicente, idealizador da campanha a favor da companheira, pudesse continuar à frente do clube paulista diante da impossibilidade de reeleição (Noronha, 2012)

Acerca da eleição de Patrícia Amorim, Stahlberg (2013, p. 105) coloca que "a sensação inicial é a de que ela foi eleita apesar de ser mulher e que erros não serão tolerados”. A afirmação, apesar de ter feito referência a uma dirigente, é passível de generalização, englobando a visão que se tem das poucas gestões femininas no futebol brasileiro. Assim como em diversas áreas, seja dentro ou fora dos esportes, algumas práticas sociais foram sendo construídas ao longo da história como essencialmente masculinas - a gestão de pessoas no esporte é uma delas (Gomes, Nassif, Mourão \& Lima, 2012). Rocha (2006) diz de uma invisibilidade feminina em cargos de comando, acrescentando que essa exclusão das mulheres em determinados cargos se refere a uma questão de gênero, e não à falta de capacidade ou habilidade das mulheres. Nesse sentido, o caso mais atual de gestão feminina no futebol é o de Myrian Fortuna, presidente do Tupi Football Club, de Minas Gerais, única mulher a comandar um clube profissional, considerando as quatro séries (A, B, C e D) do Campeonato Brasileiro - existem outros casos em clubes que não disputas as referidas competições nacionais. Myrian destaca o preconceito que sofre por ser mulher e dirigente, afirmando que chegou a perder patrocínios do clube pela falta de credibilidade que as pessoas conferiam ao seu cargo de gestão (Lavieri, 2015). Como já exposto anteriormente, a imagem da mulher junto ao futebol parece estar relacionada, quando não à sua beleza e atributos físicos, à incompetência que se espera de seus atos.

Apesar dos desafios existentes, algumas conquistas podem ser apontadas na gestão esportiva por mulheres. Em novembro de 2013, Izabel Montenegro e Josirene Ribeiro fizeram história, sendo eleitas, respectivamente, presidente e vice-presidente da Associação Cultural Esporte Clube Baraúnas, no Rio Grande do Norte. As mossoroenses formaram a primeira dupla de dirigentes mulheres de um clube brasileiro, administrando o Leão do Oeste pelo período de um ano (GloboEsporte. com, 2013). Diante das dificuldades enfrentadas pelas mulheres em sua inserção no futebol, sobretudo no campo da gestão, é de grande importância vislumbrar que, aos poucos, elas podem romper com o preconceito, provar sua competência e abrir caminhos para outras mulheres que desejam contribuir com a prática futebolística e com o esporte. A iniciativa da FIFA, maior entidade relacionada ao futebol do mundo, em valorizar a mulher e confiar em sua capacidade, também é outro fator que colabora com uma mudança de visão da relação mulher-futebol, buscando meios de romper com o paradigma machista ainda predominante.

\section{0 jogo}

A inserção das mulheres nos diversos papéis que envolvem o futebol não é vista como possibilidade, diferentemente do modo em que se deu a relação dos homens com a referida modalidade esportiva. Nesse sentido, a relação das mulheres com o futebol, vem sendo construída, desde os primeiros contatos entre ambos, de forma censurada, carregada de críticas e dificuldades, evidenciando a presença de uma forte questão de gênero. As mulheres, as quais tanto nos referimos, assim como os homens, se constituem como seres - são existências, e apesar de Heidegger não ter se debruçado no estudo das questões de gênero e sexualidade do ser humano, é possível fazermos alguns apontamentos sobre esse tema, especialmente no tocante à abertura e poder-ser do Dasein.

Sá (2005) lembra a condição de estar lançado no mundo que o Dasein se encontra, estando ligado a um determinado corpo e a determinadas condições factuais. A despeito de impor alguns limites, a facticidade possibilita espaços de poder-ser - sejam eles de acordo com as atribuições estabelecidas, ou contrárias, na tentativa de busca pela sua autenticidade. Acerca desta autenticidade, de início e na maior parte das vezes, a existência se dá da maneira impessoal, a partir de modelos apresentados desde sempre na vida de uma pessoa como sendo naturais e constitutivos de sua existência, não gerando reflexões nem questionamentos cotidianos. Conforme Azevedo (2013), esse modo impessoal de existir acaba por afastar o Dasein da liberdade de ser si mesmo e de empunhar seu projeto de ser. Mergulhados nesse modo-de-ser impessoal, acaba havendo uma massificação da existência e o que seria próprio de cada um passa a ser de todos e, ao mesmo tempo, de ninguém. (Heidegger, 1927/2015).

É importante considerar que as possibilidades de existir são da alçada do próprio ser, uma vez que "cada modo de existir, corresponde uma significação possível do mundo. O Dasein enquanto projeto é, simultaneamente, o projeto de seu mundo" (Sá, 2005, p. 1). Sobre isso, é possível apontar como exemplo a repercussão que gerou a reportagem à Revista Veja, feita por Linhares (2016) com Marcela Temer, esposa do então vice-presidente do país, Michel Temer, em abril de 2016. Os elogios à Marcela por ser bela, recatada e do lar, bem como a constatação que Michel é um homem de sorte (por isso), renderam uma onda de comentários acerca das possibilidades de existir dadas à mulher. Encarado de modo negativo, o título da entrevista suscitou campanhas na internet, onde as mulheres divulgavam fotos ou situações em que estariam contrariando a ordem de submissão feminina sugerida na reportagem. Em outras palavras, elas afirmavam poder-ser de formas diferentes e estarem bem com suas escolhas. Também é preciso levar em consideração que Marcela, assim como qualquer outro ser que está inserido no mundo, com seus aspectos históricos, sociais e culturais, escolhe existir bela, recatada e do lar, sem que isso se configure como algo negativo.

Ao trazermos a discussão da abertura do $D a$ - 
sein e do projeto de seu mundo para o futebol, especificamente para a relação deste com o feminino, podemos apontar que ser mulher e gostar de futebol se torna algo possível a partir dessa compreensão de que o Dasein é o seu próprio projeto de ser, mas que só se torna uma possibilidade quando uma pessoa, motivada pela angústia, considerada como ontológica (Heidegger, 1927/2015), compreende que ela é livre e responsável pelos rumos que dá ao seu existir e, desta feita, realizar escolhas com propriedade.

A nossa sociedade, enraizada por valores patriarcais em seu horizonte histórico, vincula ao gênero masculino as questões de poder, apontando as diferenças biológicas existentes para justificar essa posição (Maux, 2014). Dessa forma, apesar das conquistas alcançadas pelo movimento feminista, como já apontado, e

(...) embora possamos vislumbrar mudanças significativas no que tange aos papeis que homens e mulheres exercem na sociedade, esta ainda carrega um forte ranço nas questões de gênero e poder, que orientam e engessam homens e mulheres em determinados modos-de-ser e que apresentam o gênero masculino como superior, sinônimo de poder, força e potência (Maux, 2014, p. 18).

Já apontamos no decorrer do texto sobre o caráter indeterminado do ser, sendo possível ao $D a-$ sein exercer o seu pode-ser diante das possibilidades quando rompe com as determinações impostas pelo horizonte que o aprisiona em modos-de-ser já previamente definidos e nos quais se espera que ele se reconheça enquanto existente. Para que esse pode-ser seja exercido de forma mais própria, é preciso que "o Dasein permita a si mesmo a possibilidade de antecipação que assuma o seu próprio ser a partir de si e para si mesmo. (...) precisa (...) recuperar sua escolha mais própria, já que esta se encontra perdida no impessoal” (Sá, 2005, p. 3). Com isto posto, ao pensarmos a relação entre as mulheres e o futebol, evidenciamos a dificuldade de estabelecimento da mesma, especialmente pela sua associação à prática masculina desde os primórdios da história desse esporte. Mas, afinal, existem limites para a entrada e permanência das mulheres no mundo futebolístico? Quem os impõe? Que situações terminam por prejudicar e impulsionar essa relação? Compreendemos como multifatoriais os elementos que influenciam e constituem essa relação e, assim sendo, buscamos expor e discutir alguns deles.

De acordo com Vieira (2010), é a construção histórica e social de uma mentalidade antiquada que reproduz, e nos faz ouvir, desde crianças, que futebol é coisa de homem. A reprodução citada pelo autor, logo nos remete à impessoalidade apontada por Heidegger (19272015), onde o impessoal é remetido aos outros e "todo mundo é o outro e ninguém é si mesmo” (p. 185). Dessa forma, desde a mais tenra idade, é transmitida a ideia de que o futebol é campo e propriedade somente dos meninos. Sobre isso, Mourão e Morel (2005) apontam que
(...) a construção cultural brasileira concebe o esporte, e especialmente o futebol, como um espaço de práticas sociais masculinas através da sua história. E o futebol como uma prática esportiva identitária da construção deste masculino terminou por concentrar uma resistência, ainda maior do que os outros esportes, à prática feminina (p. 79).

A dificuldade do público feminino em estabelecer relações plenas e autênticas com o futebol, termina por contribuir com o ciclo vicioso do discurso de ausências, apontado por Kessler (2015). De acordo com a autora, esse discurso é definido como "uma construção discursiva na qual é (re)afirmada a centralidade e a importância do futebol dos homens (em especial o espetacular)" (p. 58). Mesmo diante das conquistas femininas no futebol, o discurso das ausências continua a subvalorizar esses ganhos, evidenciando as carências existentes, sempre em comparação com a prática masculina. Romper com esse discurso se mostra difícil devidos aos valores financeiros e simbólicos envolvidos (Kessler, 2015). A estrutura circular, ainda de acordo com Kessler (2015), compõe o discurso das ausências e apresenta os seguintes elementos: falta de incentivos, ausência de projetos duradouros, insignificante base de atletas, fraca performance, pouco espectadores, pequena visibilidade na mídia e escassos patrocínios. Percebe-se que esse círculo é vicioso, e cada um dos seus pontos, desencadeia o anterior. Ora, quando não há incentivo, seja por parte da CBF ou Federações estaduais, dificilmente haverá a execução de projetos duradouros, o que significa falta de apoio na formação de atletas, que diante de uma (não necessária, mas real) baixa performance, não chama a atenção do público, da mídia e dos patrocínios, retornando à falta de investimento inicial.

O movimento de legitimação de poder-ser em relação ao futebol, por parte das mulheres, parece, aos poucos, estar sendo melhor visto. Em artigo vinculado à revista Exame, Portugal (2014) noticiou a parceria entre a Heineken, marca de cerveja e patrocinadora oficial da UEFA Champions League, com a loja de sapatos ShoeStock. O objetivo? Entreter as mulheres nas lojas e site com promoções, no momento do jogo, para que elas pudessem liberar os maridos e namorados para assistir à final do campeonato sossegados. A repercussão não foi positiva. Podemos observar que esse tipo de colocação polariza o poder-ser do Dasein em suposições de gêneros. As mulheres têm que gostar de sapatos, e não de futebol? Aliás, não podem gostar de sapatos e de futebol? Em 2016, entretanto, a Heineken se retratou ao pensar em uma propaganda que considera as possibilidades além dos estereótipos de gênero. Como exposto em reportagem do G1.com (2016), a empresa selecionou casais e ofereceu aos homens dois presentes: um fim de semana em um spa, para suas acompanhantes e, para eles, a possibilidade de assistir à final da Champions em um evento exclusivo da Heineken. Os três homens envolvidos aceitaram a proposta. No dia do jogo, já no evento, eles entraram em contato com as suas 
mulheres, que supostamente estavam cuidando da beleza, mas foram surpreendidos ao vê-las em Milão, assistindo in loco a final da mais importante competição europeia. O vídeo, que foi amplamente elogiado, além de comentado e compartilhado nas redes sociais, é encerrado com a frase: "já pensou que ela pode gostar de futebol tanto quanto você?”. Apesar de aparentemente simples, o questionamento provoca reflexões que contrariam a ordem que está dada pela questão de gênero, naturalizando as escolhas por afinidade, de acordo com a individualidade de cada ser.

\section{Considerações finais: Acréscimos}

Diante das reflexões realizadas, não ousamos falar que as mulheres não possuem lugar no futebol - seria injusto diante do que foi alcançado nas diversas áreas que envolvem essa modalidade esportiva. Insistimos, entretanto, que elas ainda não adquiriram, efetivamente, sua capacidade de poder-ser. As mulheres parecem ser subestimadas e subutilizadas em seu potencial, principalmente em razão das concepções ligadas ao gênero que são previamente dadas em nossa sociedade e pelo horizonte histórico que nos constitui como seres. Estes estabelecidos modos-de-ser cotidianos, como apontam Roehe e Dutra (2014), terminam por ditar ao Dasein a forma como deve viver - sendo através desta forma generalizada de conduzir a vida, seguindo o que todos fazem, que o ser perde a sua individualidade e entra no que Heidegger chama de impessoalidade. Quando fazemos uma escolha motivada pela impessoalidade, retiramos do Dasein a responsabilidade por suas decisões, deixando-as mais fáceis, uma vez que as escolhas e julgamentos já estão dados (Roehe \& Dutra, 2014). No momento em que acatamos as visões e decisões dos outros sobre nosso modo-de-ser próprio, somos aprisionados em modelos que podem não nos caber, aniquilando nosso potencial de poder-ser mais próprios. Nesse sentido, percebemos que muitas pessoas em nossa sociedade, homens e mulheres, reforçam e vivem de acordo com a vinculação do futebol com o gênero masculino, não considerando outros modos-de-ser para si e para o outro. As mulheres que buscam adentrar nesse universo previamente estabelecido como masculino, sejam como jogadoras, torcedoras, árbitras, técnicas e dirigentes, terminam por romper com esse modelo cristalizado.

Ir de encontro ao que está posto e sustentar as decisões que lhe são próprias não é fácil. Entretanto, a possibilidade de escolher como conduzir a própria vida é real, mesmo diante da participação em um cotidiano impessoal. Roehe e Dutra (2014) refletem que é perante à angústia de não ser si próprio que rompemos com a impessoalidade cotidiana com a qual nos identificávamos, tornando estranho algo que soava familiar. Com a perda da familiaridade que a impessoalidade causava, o Dasein, singularizado, passa a se ver diante de si e a enxergar como possibilidades de ser a propriedade e impropriedade. Para apropriar-se de si e responsabilizar-se por suas decisões, é preciso que o Dasein compreenda o apelo da consciência, que se configura como possibilidade de escuta própria, e abandone a escuta da “falação" impessoal determinada a priori (Roehe \& Dutra, 2014). Assim sendo, a relação entre a mulher e o futebol, considerando a inclusão feminina em diversos espaços e papéis desse contexto, oscilam entre o esforço de autenticidade das mulheres em poder-ser e sua condição de ser-no-mundo que cristaliza modos-de-ser e possibilidades de existir.

Heidegger (2012) nos traz que "a essência de construir é deixar-habitar” (p. 139). Dessa forma, a possibilidade de construção se articula a partir da capacidade de se habitar. Quando as mulheres, mesmo contrariando o horizonte histórico que se apresenta para elas, buscam habitar seu modo-de-ser mais próprio em sua relação com o futebol, ocupando seus espaços e habitando seus papéis, promovem a construção desses mesmos espaços e papéis. A medida em que habitam e constroem, as mulheres envolvidas com o futebol vão habitando um lugar que passa as constituir, bem como, não raro, terminam por inspirar aquelas que desejam se lançar ao seu próprio habitar e construir sua relação com o futebol.

Considerando a importância do futebol como cultura nacional, assim como a construção do mesmo como um espaço não naturalizado como feminino, se faz importante a discussão e desconstrução das questões de gênero no futebol, visando desmitificar e valorizar uma prática já existente, porém ainda não consolidada, em nosso país.

\section{Referências}

Castellani Filho, L. (1988). Educação física no Brasil: a história que não se conta. Campinas: Papirus Editora.

Azevedo, A.K.S. (2013). Não há você sem mim: histórias de mulheres sobreviventes de uma tentativa de homicídio. Tese de Doutorado, Universidade Federal do Rio Grande do Norte, Natal, RN, Brasil.

Confederação Brasileira de Futebol (2013, março 27). Emily Lima é a primeira técnica da Seleção Feminina. Recuperado de http://www.cbf. com.br/noticias/selecao-base-feminina/emily-lima-e-a-primeira-tecnica-da-selecao-feminina\#.V5-ZavkrLIU

Confederação Brasileira de Futebol (2014, fevereiro 04). Arbitragem feminina brasileira em alta. Recuperado de https://www.cbf.com.br/noticias/arbitragem/arbitragem-feminina-brasileira-em-alta\#.Wlv3XVWnHIV

Confederação Brasileira de Futebol (2016, novembro 01). Emily Lima é a nova técnica da Seleção Feminina. Recuperado de https://selecao. cbf.com.br/noticias/selecao-feminina/emily-lima-e-a-nova-tecnica-da-selecao-brasileira\# . WmI6MVWnHIU 
Correia, J. M., \& Rigo, L.C. (2013). Emergência do futebol no início do século XX: olhares sobre a disseminação e popularização do esporte bretão em diferentes regiões do território brasileiro”. Revista Didática Sistêmica, Edição Especial, 195-208. Recuperado de https://www. seer.furg.br/redsis/article/view/4181/2728

Decreto Lei $\mathrm{n}^{\circ}$ 3.199/1941. (1941). Estabelece as bases de organização dos desportos em todo o país. Diário Oficial da União. Recuperado de https://www.planalto.gov.br/ccivil 03/decreto-lei/1937-1946/del3199.htm

Deliberação no 10/1979. (1979). Conselho Nacional de Desportos. Baixa instruções às entidades desportivas do país para a prática de desportos pelas mulheres. Diário Oficial da União. Recuperado de https://www.jusbrasil.com.br/ diarios/3438879/pg-92-secao-1-diario-oficial-da-uniao-dou-de-31-12-1979

Dibradoras. (2017, setembro 22). Demissão de Emily Lima: nos últimos 13 anos, todos os técnicos que passaram pela seleção tiveram mais tempo do que ela. Recuperado de http://dibradoras. com.br/demissao-de-emily-lima-nos-ultimos-13-anos-todos-os-tecnicos-que-passaram-pela-selecao-tiveram-mais-tempo-que-ela/

Duarte, M., Garcia, S., \& Luz, S.R. (1996, setembro). Dossiê: Valeu meninas! E agora? Placar, 27(1119), 46-54.

Duque, A. P., \& Hedler, L. (2012, agosto 19). Londres 2012: a olimpíada das mulheres [Blog]. Recuperado de https://petdirunb.wordpress. com/2012/08/19/londres-2012-a-olimpiada-das-mulheres/

Echeverria, R. (1984, julho). O charme vai a campo. Placar, 15(738), 24-27. Recuperado de https:// books.google.com.br/books?id =3VxTL4P3bV4C\&pg = PA5\&num =6\&as pt = MAGAZINES\&hl $=$ pt-BR\&source $=$ gbs toc\&cad $=2 \#-$ $\mathrm{v}=$ onepage $\& \mathrm{q} \& \mathrm{f}=$ true

Elmôr, M.G. (2002). Masculinidade em jogo: um estudo sobre papéis masculinos num grupo de adolescentes no futebol. Dissertação de Mestrado, Universidade Estadual de Campinas, Campinas, SP, Brasil.

FoxSports (2015, janeiro 11). Técnica deixa base da Seleção para comandar o São José. Recuperado de http://www.foxsports.com.br/news/185148tecnica-deixa-base-da-selecao-para-comandar-o-sao-jose

Franzini, F. (2005). Futebol é “coisa para macho”? Pequeno esboço para uma história das mulheres no país do futebol. Revista Brasileira de História, 25(50), 315-328. Recuperado de http://www.scielo.br/scielo.php?script=sci $\underline{\text { arttext\&pid }=\text { S0102-01882005000200012 }}$
Franco Júnior, H. (2007). A dança dos deuses: futebol, sociedade e cultura. São Paulo: Companhia das Letras.

G1.com (2016, junho 06). Em campanha, homens "despacham" mulheres para spa e recebem ligação. G1.com. Recuperado de http:// g1.globo.com/economia/midia-e-marketing/ noticia/2016/06/em-campanha-homens-despacham-mulheres-para-spa-e-recebem-licao. $\underline{\mathrm{html}}$

GloboEsporte.com. (2013, novembro 04). Baraúnas é primeiro clube do país a ter presidente e vice mulheres. Recuperado de http://globoesporte. globo.com/rn/noticia/2013/11/baraunas-e-primeiro-clube-do-pais-ter-presidente-e-vice-mulheres.html

Gomes, E., Nassif, V., Mourão, L., \& Lima, E. O. (2012). As representações da mídia sobre a gestão feminina no Clube de Regatas Flamengo. Podium: Sport, Leisure and Tourism Review, 1(1), 151-173. Recuperado de http://www.podiumreview.org.br/ojs/index.php/rgesporte/ar$\underline{\text { ticle/view/20 }}$

Heidegger, M. (2012). Ensaios e conferências. (M.S.C. Schuback, Trad). Petrópolis: Vozes.

Heidegger, M. (2015). Ser e tempo (M. S. Cavalcante, Trad.). Petrópolis: Vozes. (Obra original publicada em 1927).

Klessler, C. S. (2015). Mais que Barbies e ogras: uma etnografia do futebol de mulheres no Brasil e nos Estados Unidos. Tese de Doutorado, Universidade Federal do Rio Grande do Sul, Porto Alegre, RS, Brasil.

Lavieri, D. (2015, novembro 28). Presidente do Tipi relata preconceito por ser mulher: "perdi patrocínio". Recuperado de http://esporte.uol. com.br/futebol/ultimas-noticias/2015/11/28/ perdi-patrocinadores-so-porque-sou-mulher-revela-presidente-do-tupi-mg.htm

Leite, A. (2017, setembro 10). Mulheres se prepararam para voltar a apitar na elite do futebol do país. Estadão. Recuperado de http://esportes. estadao.com.br/noticias/futebol,mulheres-se-preparam-para-voltar-a-apitar-na-elite-do-futebol-do-pais, 70001981098

Linhares, J. (2016, abril 18). Marcela Temer: bela, recatada e "do lar". Revista Veja. Recuperado em 10 de agosto, de http://veja.abril.com.br/ brasil/marcela-temer-bela-recatada-e-do-lar/

Maia, J. P. (2014, novembro 01). Dia da Mulher: primeira treinadora de time masculino relembra experiências. Recuperado de http://globoesporte.globo.com/ac/noticia/2013/03/dia-da-mulher-primeira-treinadora-de-time-masculino-relembra-experiencia.html 
Maux, A. A. B. (2014). Masculinidade à prova: um estudo de inspiração fenomenológico-hermenêutico sobre a infertilidade masculina. Tese de Doutorado, Universidade Federal do Rio Grande do Norte, Nata, RN, Brasil.

Mello, J. (2015, março 08). Histórias incríveis: Léa Campos supera ditadura, detenção e a CBF pelo apito. Recuperado de http://globoesporte. globo.com/futebol/noticia/2015/03/historias-incriveis-lea-campos-supera-ditadura-detencao-e-cbd-pelo-apito.html

Melo, V. A. (2007). Mulheres em movimento: a presença feminina nos primórdios do esporte na cidade do Rio de Janeiro (até 1910). Revista Brasileira de História, 27(54), 127-152. Recuperado de http://www.educadores.diaadia.pr. gov.br/arquivos/File/2010/artigos teses/2010/ Historia/artigos/3melo victor artigo.pdf

Mendonça, R. (2016, junho 15). Inexperiente, Dunga teve as chances que mulheres mais preparadas que eles nunca conseguiram na CBF. Por quê?. Recuperado de http://dibradoras.com.br/ inexperiente-dunga-teve-as-chances-que-mulheres-mais-preparadas-que-ele-nunca-conseguiram-na-cbf-por-que/

Mendonça, R. (2017, outubro 06). Com o apoio de Sissi e Formiga, jogadoras e veteranas fazem apelo à CBF por mudanças no futebol feminino. Recuperado de http://dibradoras.com.br/ com-o-apoio-de-sissi-e-formiga-jogadoras-e-veteranas-fazem-apelo-cbf-por-mudancas-no-futebol-feminino/

Miragaya, A. (2008). As mulheres nos jogos olímpicos: participação e inclusão social. In Rubio, K. Megaeventos esportivos, legado e responsabilidade social (pp. 229-246) Recuperado de https://books. google.com.br/books?id = 8xlp1Dcush8C\&p$\mathrm{g}=\mathrm{PA} 229 \& \operatorname{lpg}=\mathrm{PA} 229 \& \mathrm{dq}=\mathrm{As}+$ mulheres +nos + Jogos +Ol\%C3\%ADmpicos: + participa\%C3\%A7\%C3\%A3o +e+inclus\%C3\%A3o+$\underline{\text { social }+2007 \& \text { source }=\text { bl\&ots }=\text { mTLzpVr- }}$ D76\&sig $=$ KpL3LWDKwzVxT0mibdT2Rb2cCwk\&hl =ptBR\&sa $=$ X\&ved $=0$ ahUKEwiP7K7tjtvYAhXBgZAKHWjFDUAQ6AEIRzAE\#$\mathrm{v}=$ onepage $\& \mathrm{q}=\mathrm{As} \% 20 \mathrm{mulheres} \% 20$ nos\%20 Jogos\%200l\%C3\%ADmpicos\%3A\%20partiсіра\%С3\%A7\%C3\%A30\%20e\%20inclus\%C3\%A3o\%20social\%202007\&f=false

Moreira, A. P., \& Pedrosa, A. P. (2016, fevereiro 28). Torcedoras ainda são desconhecidas pelos clubes de futebol. O Tempo. Recuperado de http:// www.otempo.com.br/superfc/torcedoras-ainda-s\%C3\%A3o-desconhecidas-pelos-clubes-de-futebol-1.1244097

Moura, E. J. L. (2003). As relações entre lazer, futebol e gênero. Tese de Doutorado, Universidade Estadual de Campinas, Campinas, SP, Brasil.
Moura, E.J.L. (2003). As relações entre lazer futebol e gênero. Dissertação de Mestrado, Universidade Estadual de Campinas, Campinas, SP, Brasil.

Mourão, L. \& Morel, M. (2005). As narrativas sobre o futebol feminino: o discurso da mídia impressa em campo. Revista Brasileira de Ciências do Esporte, 26(2), 73-86. Recuperado de http:// www.redalyc.org/pdf/4013/401338509006.pdf

Noronha, M. P. (2012, julho). Sou mulher! Sou gremista! Representações da mulher no futebol e as cristalizações de gênero envolvidas neste processo: uma etnografia sobre torcedoras do Grêmio. Anais do XI Encontro Estadual de História, Rio Grande, RS, Brasil.

Observador. (2017, outubro 03). Terramoto na seleção brasileira de futebol feminino: cinco jogadoras abandonam a equipa. Recuperado de http://observador.pt/2017/10/03/terramoto-na-selecao-brasileira-de-futebol-feminino-cinco-jogadoras-abandonam-a-equipa/

Oliveira, A. F. de. (2012). Origem do futebol na Inglaterra e no Brasil. Revista Brasileira de Futsal e Futebol, 4(13), 170-174. Recuperado de http://www.rbff.com.br/index.php/rbff/article/ viewFile/154/139

Oliveira, F.P. (2006). A inserção da mulher no ambiente desportivo. Arquivos em movimento, 2(1), 1-10. Recuperado de http://www.ceme. eefd.ufrj.br/ive/boletim/bive200608/noticias/ artigo08 v2n1.pdf

Portugal, M. (2014, maio 23). Futebol ou sapatos? Ação da Heineken divide consumidores. Revista Exame. Recuperado de http://exame.abril. com.br/marketing/noticias/heineken-cria-liquidacao-de-sapatos-durante-final-da-uefa

Rebouças, M. S. S., \& Dutra, E. (2017). Tematizando sobre liberdade, escolha e culpa na vivência do abortamento provocado. In E. Dutra \& A.A.B. Maux (Org), Pesquisa em Psicologia Fenomenológico-existencial: interpretações do sofrimento na contemporaineidade. Curitiba: CRV.

Rocha, C. T. C. (2006). Gênero em ação: Rompendo o teto de vidro? (Novos Contextos da Tecnociência). Tese de Doutorado, Universidade Federal de Santa Catarina, Florianópolis, SC, Brasil.

Rocha, F. (2015, junho 20). Mulheres no comando? Até na Copa feminina elas são minoria. Recuperado de http://esporte.uol.com.br/futebol/ ultimas-noticias/2015/06/20/mulheres-no-comando-ate-na-copa-feminina-elas-sao-minoria.htm

Rocha Junior, C. P., \& Santo, F. R. E. (2011). Futebol em Salvador: o início de uma história (18991920). Movimento, 17(3), 79-95. Recuperado de http://seer.ufrgs.br/index.php/Movimento/ article/view/17683/17737 
Rodrigues, C. (2010). Diferença sexual, direitos e identidade: um debate a partir do pensamento da desconstrução. Cadernos Pagu, (34), 209-233. Recuperado de http://www. scielo.br/scielo.php?script $=$ sci arttext\&pi$\mathrm{d}=$ S0104-83332010000100009

Roehe, M. V., \& Dutra, E. (2014). Dasein, o entendimento de Heidegger sobre o modo de ser humano. Avances en Psicología Latinoamericana, 32(1), 105-113. Recuperado de http://www. scielo.org.co/pdf/apl/v32n1/v32n1a08.pdf

Sá, R. N. (2005, maio). A analítica Heideggeriana da existência em "Ser e tempo". Anais da VJornada IFEN, Rio de Janeiro, RJ, Brasil.

Santos, J. M. C. M. (2010). Revolução vascaína: a profissionalização do futebol e a inserção socioeconômica de negros e portugueses na cidade do Rio de Janeiro (1915-1934). Tese de Doutorado, Universidade de São Paulo, São Paulo, SP, Brasil.

Senkevics, A. (2012, julho 31). Um breve histórico da participação das mulheres nos Jogos Olímpicos [Blog]. Recuperado de https://ensaiosdegenero.wordpress.com $/ 2012 / 07 / 31 /$ um-historico-da-participacao-das-mul$\underline{\text { heres-nos-jogos-olimpicos/ }}$

Stahlberg, L. T. (2013). Mulheres em campo: novas reflexões acerca do feminino no futebol. Dissertação de Mestrado, Universidade Federal de São Carlos, São Carlos, SP, Brasil.

Souza, O.M, Jr. (2013). Futebol como projeto profissional de mulheres: interpretações da busca pela legitimidade. Tese de Doutorado, Universidade Estadual de Campinas, Campinas, SP, Brasil.

Vieira, V. (2010). Sentidos que norteiam a participação das torcedoras nos estádios de futebol. Tese de Doutorado, Universidade do Estado do Rio de Janeiro, Rio de Janeiro, RJ, Brasil.

Wenetz, I. (2005). Gênero e sexualidade nas brincadeiras do recreio. Dissertação de Mestrado, Universidade Federal do Rio Grande do Sul, Porto Alegre, RS, Brasil.
Larissa Medeiros de Souza, Universidade Federal do Rio Grande do Norte. Endereço Institucional: Rua Alterosa, 4923 (Neópolis). CEP 59084-460. Natal/RN. EMail: larissams.psi@gmail.com

Ana Andréa Barbosa Maux, Centro Universitário Facex, Natal, Rio Grande do Norte.

Melina Séfora Souza Rebouças, Centro Universitário do Rio Grande do Norte.

Recebido em 26.09.2017 Primeira Decisão Editorial em 26.11.2017 Aceito em 05.05.2018 